\title{
Guidelines in review: Comparison of ESC and AHA guidance for the diagnosis and management of infective endocarditis in adults
}

\author{
David J. Murphy, MD, ${ }^{\mathrm{a}}$ Munaib Din, BSc, ${ }^{\mathrm{a}}$ Fadi G. Hage, MD, FASNC, ${ }^{\mathrm{b}, \mathrm{c}}$ \\ and Eliana Reyes, MD, PhD, FESC ${ }^{\mathrm{a}, \mathrm{d}}$ \\ a King's College London and Guy's and St Thomas' NHS Foundation Trust PET Centre, London, \\ UK \\ b Division of Cardiovascular Disease, Department of Medicine, The University of Alabama at \\ Birmingham, Birmingham, AL \\ c Section of Cardiology, Birmingham Veteran Affairs Medical Center, Birmingham, AL \\ d Nuclear Medicine Department, Royal Brompton and Harefield NHS Foundation Trust, London, \\ UK
}

Received May 24, 2018; accepted May 24, 2018

doi: $10.1007 / \mathrm{s} 12350-018-1333-5$

Over recent years, new evidence has led a rethinking of the available guidance on the diagnosis and management of infective endocarditis (IE). This review compares the most recently available guidance provided by the American Heart Association (AHA) IE Writing Committee, and the Task Force for the management of IE of the European Society of Cardiology (ESC). This represents the sixth of a new series of comparative guidelines review published in the Journal. (J Nucl Cardiol 2019;26:303-8.)

Key Words: Infection • image-guided application $\cdot$ multimodality

\begin{tabular}{|c|c|c|c|}
\hline \multicolumn{2}{|c|}{ Abbreviations } & MRI & Magnetic resonance imaging \\
\hline CTCA & tomographic & MRA & Magnetic resonance angiography \\
\hline & angiography & NSER & equivalent \\
\hline CDRIE & device-related & & recommendation \\
\hline & endocarditis & PET/ & Positron emission tomography/com- \\
\hline DSA & Digital subtraction angiography & $\mathrm{CT}$ & puted tomography \\
\hline${ }^{18} \mathrm{~F}-$ & 18-fluorodeoxyglucose & TEE & Transesophageal echocardiography \\
\hline FDG & & TTE & Transthoracic echocardiography \\
\hline IE & Infective endocarditis & & \\
\hline LOE & Level of evidence & & \\
\hline
\end{tabular}

\section{See related editorial, pp. 309-312;}

\section{pp. 313-315}

\footnotetext{
Reprint requests: Eliana Reyes, MD, PhD, FESC, Nuclear Medicine Department, Royal Brompton and Harefield NHS Foundation Trust, Sydney Street, London, SW3 6NP, UK; e.reyes@rbht.nhs.uk 1071-3581/ $\$ 34.00$

Copyright (c) 2018 The Author(s)
}

Over recent years, new evidence has led to a rethink of the available guidance on the diagnosis and management of infective endocarditis (IE). This review compares the most recently available recommendations provided by the American Heart Association (AHA) IE Writing Committee, and the Task Force for the management of IE of the European Society of Cardiology (ESC). ${ }^{1,2}$ Class (I, II or III) and level of evidence (A, B 
or C) are provided for each recommendation where given by the guidelines (Tables 1, 2, 3; Figures 1, 2). As in previous comparative guidelines reviews published in the Journal, ${ }^{3-7}$ this review focuses on the role of imaging in the evaluation and management of patients with suspected IE.

Table 1. Indications for echocardiography in patients with suspected infective endocarditis

\begin{tabular}{|c|c|c|c|c|}
\hline \multirow{2}{*}{ Recommendation } & \multicolumn{2}{|c|}{ ESC } & \multicolumn{2}{|c|}{ AHA } \\
\hline & Class & LOE & Class & LOE \\
\hline \multicolumn{5}{|l|}{ Diagnosis } \\
\hline $\begin{array}{l}\text { Echocardiography is recommended as the first-line imaging test in all } \\
\text { cases of suspected IE, and it should be performed as soon as possible } \\
(<12 \text { hours after initial evaluation)* }\end{array}$ & I & B & 1 & A, B \\
\hline $\begin{array}{l}\text { TEE should be performed if initial TTE is negative or non-diagnostic in } \\
\text { patients for whom there is an ongoing suspicion for IE }\end{array}$ & 1 & B & 1 & B \\
\hline $\begin{array}{l}\text { TEE is recommended if there is concern for intracardiac complications } \\
\text { in patients with an initial positive TTE }\end{array}$ & \multicolumn{2}{|c|}{ NSER } & 1 & B \\
\hline $\begin{array}{l}\text { TEE is recommended in patients with clinical suspicion of IE when a } \\
\text { prosthetic heart valve or an intracardiac device is present }\end{array}$ & 1 & B & \multicolumn{2}{|c|}{ NSER† } \\
\hline $\begin{array}{l}\text { Repeat TEE is recommended within } 3-7 \text { days, }{ }^{\ddagger} \text { or sooner if clinical } \\
\text { findings change, in patients for whom there is a high suspicion of IE } \\
\text { despite an initial negative TEE }\end{array}$ & 1 & C & 1 & B \\
\hline $\begin{array}{l}\text { TEE should be considered even in patients with positive TTE, except in } \\
\text { isolated right-sided native valve IE with good quality TTE and } \\
\text { unequivocal echocardiographic findings }\end{array}$ & Ila & C & \multicolumn{2}{|c|}{ NSER } \\
\hline $\begin{array}{l}\text { Echocardiography should be considered in Staphylococcus aureus } \\
\text { bacteraemia }\end{array}$ & Ila & B & \multicolumn{2}{|c|}{ NSER } \\
\hline \multicolumn{5}{|l|}{ Intraoperative echocardiography } \\
\hline $\begin{array}{l}\text { Intraoperative echocardiography is recommended in all cases of IE } \\
\text { undergoing surgery }\end{array}$ & 1 & B & \multicolumn{2}{|c|}{ NSER } \\
\hline \multicolumn{5}{|l|}{ Follow-up } \\
\hline $\begin{array}{l}\text { Repeat TEE should be performed after an initially positive TEE if } \\
\text { clinical suspicion of a new complication of IE arises (e.g. persistent } \\
\text { fever, changes in cardiac murmurs, heart failure, embolism, new } \\
\text { atrioventricular block, or arrhythmia) }\end{array}$ & 1 & B & I & B \\
\hline $\begin{array}{l}\text { Repeat TTE and/or TEE is recommended during follow-up of } \\
\text { uncomplicated IE to detect new silent complications and monitor } \\
\text { vegetation size }\end{array}$ & Ila & B & \multicolumn{2}{|c|}{ NSER } \\
\hline $\begin{array}{l}\text { TTE is recommended at the time of antimicrobial therapy completion } \\
\text { to evaluate cardiac and valve morphology and function }\end{array}$ & 1 & C & Ila & C \\
\hline
\end{tabular}

* According to the AHA scientific statement, TEE is preferred over TTE, but the latter should be performed if TEE is not immediately available. TTE may be sufficient in small children

${ }^{\dagger} \mathrm{AHA}$ statement also suggests TEE as first-line test in patients with a prosthetic valve and suspected IE

In this clinical scenario, the AHA statement recommends repeating the TEE in 3 to 5 days or sooner

${ }^{\S}$ ESC guidelines stipulate that the timing and mode (TTE or TEE) of repeat test depend on initial findings, microorganism type, and initial response to therapy 
Table 2. indications for non-invasive imaging in cardiac device-related infective endocarditis (CDREI)

\begin{tabular}{|c|c|c|c|c|}
\hline \multirow{2}{*}{ Recommendation } & \multicolumn{2}{|c|}{ ESC } & \multicolumn{2}{|c|}{ AHA } \\
\hline & Class & LOE & Class & LOE \\
\hline $\begin{array}{l}\text { TEE is recommended in patients with suspected CDRIE with } \\
\text { positive or negative blood cultures, independent of TTE } \\
\text { results, to evaluate lead-related IE and heart valve infection }\end{array}$ & 1 & C & \multicolumn{2}{|c|}{ NSER } \\
\hline $\begin{array}{l}\text { Intracardiac echocardiography may be considered in } \\
\text { patients with suspected CDRIE, positive blood cultures and } \\
\text { negative TTE and TEE results. }\end{array}$ & $\mathrm{Ilb}$ & C & \multicolumn{2}{|c|}{ NSER } \\
\hline $\begin{array}{l}\text { Radiolabelled leucocyte scintigraphy and }{ }^{18} \mathrm{~F}-\mathrm{FDG} \text { PET/CT } \\
\text { imaging may be considered additional tools in patients with } \\
\text { suspected CDRIE, positive blood cultures and negative } \\
\text { echocardiography }\end{array}$ & $\mathrm{Ilb}$ & C & \multicolumn{2}{|c|}{ NSER } \\
\hline
\end{tabular}


Table 3. Role of CT, MRI, radionuclide imaging and angiography in the assessment of IE patients

\begin{tabular}{|c|c|c|c|c|}
\hline Established and proposed indications for advanced imaging in IE & \multicolumn{2}{|c|}{ ESC } & \multicolumn{2}{|c|}{ AHA } \\
\hline$C T$ & Class & LOE & Class & LOE \\
\hline $\begin{array}{l}\text { Cardiac CT may be used in cases in which definitive evidence of IE } \\
\text { and its complications is not secured with TEE }\end{array}$ & & & \multicolumn{2}{|c|}{$\mathrm{Y}^{*}$} \\
\hline $\begin{array}{l}\text { CTCA can be used as an alternative to invasive coronary angiography } \\
\text { in patients with IE }\end{array}$ & \multicolumn{2}{|c|}{$\mathrm{Y}^{*}$} & \multicolumn{2}{|c|}{$\mathrm{Y}^{*}$} \\
\hline $\begin{array}{l}\text { Cardiac CT can be used to detect abscesses/pseudoaneurysms in } \\
\text { native valve IE, and to assess the extent of any perivalvular } \\
\text { complication }\end{array}$ & \multicolumn{2}{|c|}{$\mathrm{Y}^{*}$} & & \\
\hline CT may help surgical planning in aortic IE & \multicolumn{2}{|c|}{$\mathrm{Y}^{*}$} & \multicolumn{2}{|c|}{$\mathrm{Y}^{*}$} \\
\hline $\begin{array}{l}\text { CT can be used to identify pulmonary abscesses and infarcts in right- } \\
\text { sided IE }\end{array}$ & \multicolumn{2}{|c|}{$\mathrm{Y}^{*}$} & & \\
\hline $\begin{array}{l}\text { Cerebral CTA is reasonable as an initial imaging test for the detection } \\
\text { of intracranial mycotic aneurysms }\end{array}$ & Ila & B & Ila & B \\
\hline $\begin{array}{l}\text { Cerebrovascular imaging (in general) may be considered in all } \\
\text { patients with left-sided IE who have no CNS signs or symptoms }\end{array}$ & \multicolumn{2}{|c|}{ NSER } & $\mathrm{IIb}$ & $\mathrm{C}$ \\
\hline $\begin{array}{l}\text { Cerebral CTA may be used instead of MRA to diagnose cerebral } \\
\text { mycotic aneurysms in critically ill patients }\end{array}$ & \multicolumn{2}{|c|}{$\mathrm{Y}^{*}$} & \multicolumn{2}{|c|}{$\mathrm{Y}^{*}$} \\
\hline $\begin{array}{l}\text { CT/CTA can be used to detect splenic and other systemic abscesses, } \\
\text { as well as IE-related peripheral vascular complications }{ }^{+}\end{array}$ & \multicolumn{2}{|c|}{$\mathrm{NSER}^{\ddagger}$} & I & B \\
\hline \multicolumn{5}{|l|}{$M R I$} \\
\hline $\begin{array}{l}\text { Cerebral MRA may be considered as first line for the detection of } \\
\text { cerebral mycotic aneurysms }\end{array}$ & Ila & B & Ila & B \\
\hline $\begin{array}{l}\text { Cerebral MRI may be considered for better lesion characterisation in } \\
\text { IE patients with neurological symptoms }\end{array}$ & \multicolumn{2}{|c|}{$\mathrm{Y}^{*}$} & & \\
\hline \multicolumn{5}{|l|}{ Angiography } \\
\hline $\begin{array}{l}\text { Digital subtraction angiography (DSA) is reasonable as an initial } \\
\text { diagnostic test in patients with suspected cerebral mycotic } \\
\text { aneurysms }\end{array}$ & \multicolumn{2}{|c|}{ NSER } & Ila & B \\
\hline $\begin{array}{l}\text { Conventional angiography may be considered for the detection of } \\
\text { intracranial mycotic aneurysms in patients with negative CTA, MRA } \\
\text { or DSA }\end{array}$ & Ila & B & Ila & B \\
\hline \multicolumn{5}{|l|}{ Radionuclide Imaging } \\
\hline $\begin{array}{l}{ }^{18} \mathrm{~F}-\mathrm{FDG} \mathrm{PET} / \mathrm{CT} \text { and radiolabelled leucocyte scintigraphy may help } \\
\text { reduce the number of misdiagnosed IE classified in the "possible IE" } \\
\text { category of the Duke criteria }\end{array}$ & \multicolumn{2}{|c|}{$\mathrm{Y}^{*}$} & \multirow{3}{*}{\multicolumn{2}{|c|}{$Y^{\S}$}} \\
\hline $\begin{array}{l}{ }^{18} \text { F-FDG PET/CT or radiolabelled leucocyte scintigraphy may help } \\
\text { visualize peripheral emboli and metastatic infectious events }\end{array}$ & \multicolumn{2}{|c|}{$\mathrm{Y}^{*}$} & & \\
\hline $\begin{array}{l}{ }^{18} \mathrm{~F}-\mathrm{FDG} \text { PET/CT must be interpreted with caution in patients who } \\
\text { have undergone cardiac surgery within } 3 \text { months, as false positives } \\
\text { may occur due to post-operative inflammation }\end{array}$ & \multicolumn{2}{|c|}{$\mathrm{Y}^{*}$} & & \\
\hline
\end{tabular}

*These proposed indications are discussed in the guidelines but neither the ESC guidelines nor the AHA scientific statement give specific or formal recommendation

The AHA statement recommends that, in IE patients with suspected metastatic foci of infection, the choice of diagnostic technique (ultrasonography, CT or MRI) should be individualised for each patient (Class I; LOE, C)

${ }^{\ddagger}$ Although there is no specific recommendation, the ESC guidelines state that patients with suspected splenic complications should be evaluated by CT, MRI or ultrasound

${ }^{\S}$ The AHA statement recognises that more studies are needed to determine the role of ${ }^{18} \mathrm{~F}$-FDG PET/CT imaging in the diagnosis and management of patients with IE, and highlights evidence on the usefulness of this technique for the detection of peripheral emboli and other extracardiac complications 


\section{Clinically Suspected Infective Endocarditis (IE)}

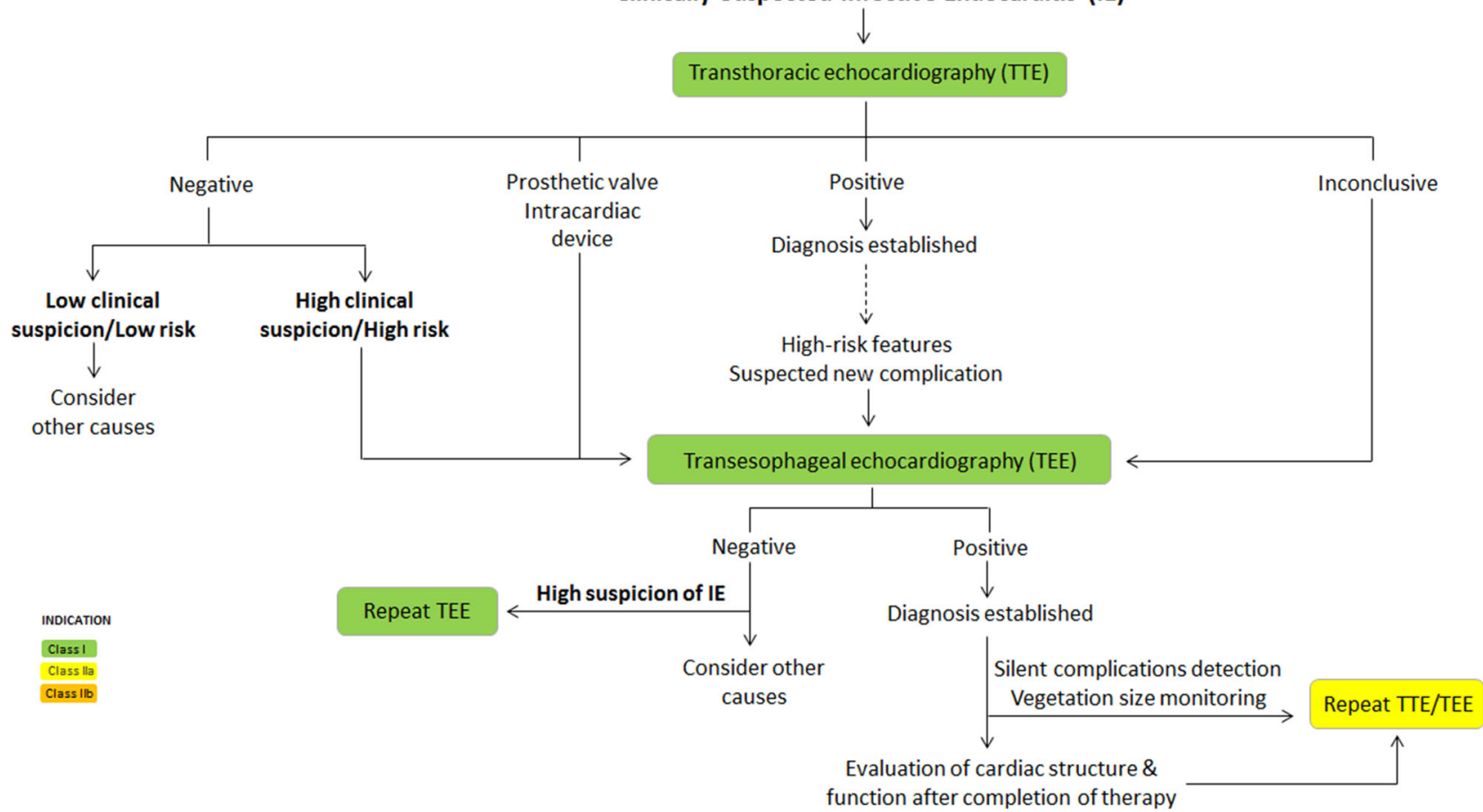

Figure 1. ESC and AHA recommendations for the initial assessment of patients with clinically suspected infective endocarditis using echocardiography.

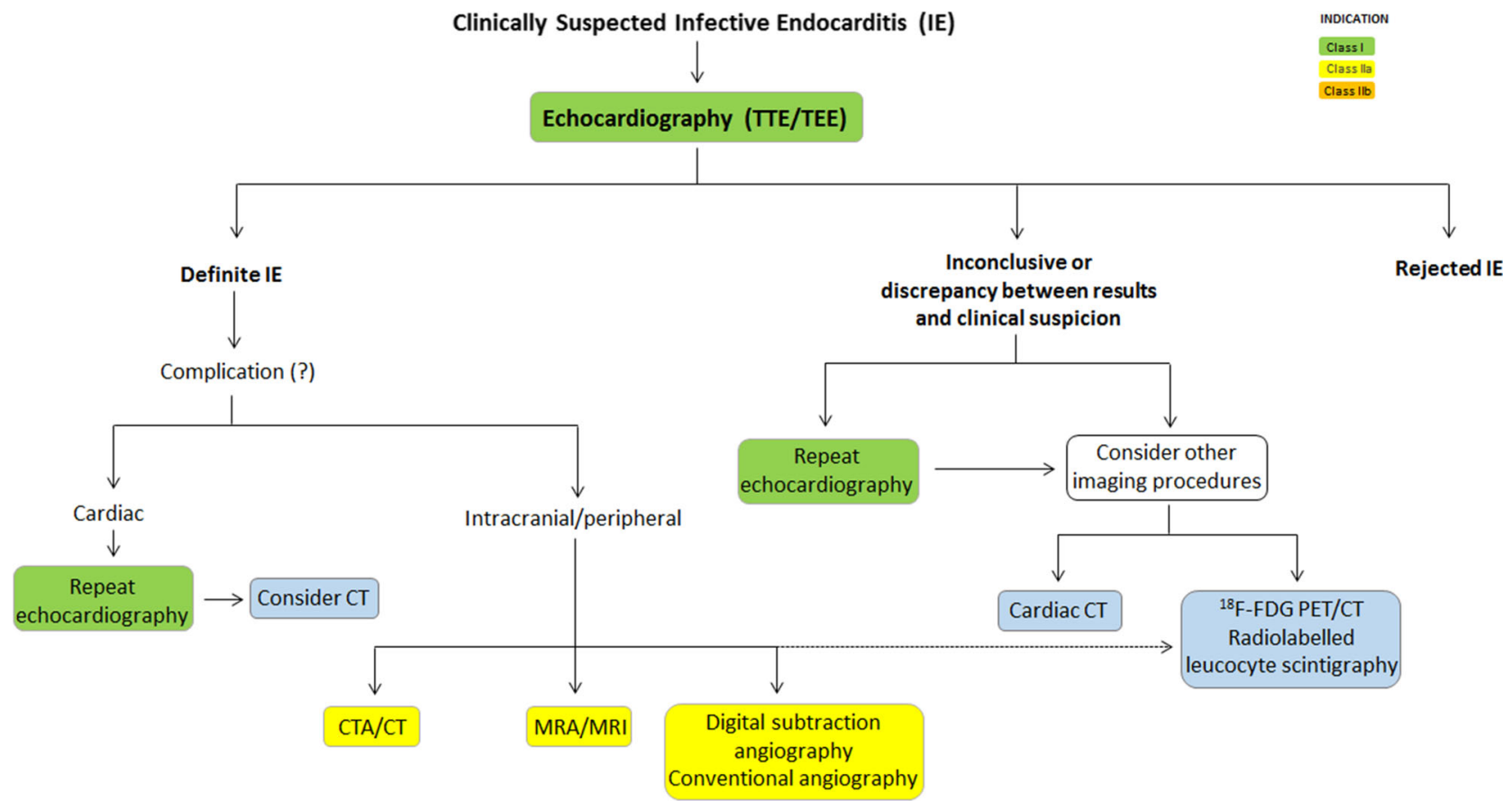

Figure 2. Role of advanced imaging in the assessment of patients with infective endocarditis. CTA, computed tomographic angiography; ${ }^{18} F-F D G, 18$-fluorodeoxyglucose; $M R A$, magnetic resonance angiography; MRI, magnetic resonance imaging; TEE, transesophageal echocardiography; TTE, transthoracic echocardiography. 


\section{Disclosure}

All authors have nothing to disclose.

\section{Open Access}

This article is distributed under the terms of the Creative Commons Attribution 4.0 International License (http:// creativecommons.org/licenses/by/4.0/), which permits unrestricted use, distribution, and reproduction in any medium, provided you give appropriate credit to the original author(s) and the source, provide a link to the Creative Commons license, and indicate if changes were made.

\section{References}

1. Baddour LM, Wilson WR, Bayer AS, Fowler VG Jr, Tleyjeh IM, Rybak MJ, et al. American Heart Association Committee on Rheumatic Fever, Endocarditis, and Kawasaki Disease of the Council on Cardiovascular Disease in the Young, Council on Clinical Cardiology, Council on Cardiovascular Surgery and Anesthesia, and Stroke Council. Infective Endocarditis in Adults: Diagnosis, antimicrobial therapy, and management of complications: A scientific statement for healthcare professionals from the American Heart Association. Circulation 2015;132:1435-86.

2. Habib G, Lancellotti P, Antunes MJ, Bongiorni MG, Casalta JP, Del Zotti F, et al. ESC Scientific Document Group. 2015 ESC guidelines for the management of infective endocarditis: The task force for the management of infective endocarditis of the European Society of Cardiology (ESC). Endorsed by: European Association for Cardio-Thoracic Surgery (EACTS), the European Association of Nuclear Medicine (EANM). Eur Heart J 2015;36:3075-128.

3. Velasco A, Reyes E, Hage FG. Guidelines in review: Comparison of the 2014 ACC/AHA guidelines on perioperative cardiovascular evaluation and management of patients undergoing noncardiac surgery and the 2014 ESC/ESA guidelines on noncardiac surgery: Cardiovascular assessment and management. J Nucl Cardiol 2017;24:165-70.

4. Stirrup J, Velasco A, Hage FG, Reyes E. Comparison of ESC and ACC/AHA guidelines for myocardial revascularization. J Nucl Cardiol 2017;24:1046-53.

5. Velasco A, Stirrup J, Reyes E, Hage FG. Guidelines in review: Comparison between AHA/ACC and ESC guidelines for the management of patients with ventricular arrhythmias and the prevention of sudden cardiac death. J Nucl Cardiol 2017;24:1902-3.

6. Prejean SP, Din M, Reyes E, Hage FG. Guidelines in review: Comparison of the 2014 AHA/ACC guideline for the management of patients with non-ST-elevation acute coronary syndromes and the 2015 ESC guidelines for the management of acute coronary syndromes in patients presenting without persistent ST-segment elevation. J Nucl Cardiol 2017. https://doi.org/10.1007/s12350-0171137-z.

7. Joseph J, Velasco A, Hage FG, Reyes E. Guidelines in review: Comparison of ESC and ACC/AHA guidelines for the diagnosis and management of patients with stable coronary artery disease. $\mathbf{J}$ Ncl Cardiol 2018;25:509-15. 